\title{
Surface Characterisation of Bioactive Titanium Formed Via Anodic Oxidation
}

\author{
M.A. Selimin, Z. Malik, N. Anjang, M.I. Idris, and H.Z. Abdullah
}

\begin{abstract}
Anodic oxidation (AO) is one of surface modification method that able to produce specific topographies and enhance bone growth of the titanium (Ti). Modifying the oxide layer of titanium from smooth (bioinert) to rough/porous (bioactive) surface makes this material able to be used as artificial implant for biomedical application. In this study, the effect of $\mathrm{AO}$ on the characteristics of titanium in different electrolytes is evaluated. Anodised Ti was prepared using AO method in two different electrolytes (acetic and sulphuric acid) with same concentration $(0.3 \mathrm{M})$. The applied voltage were varied range $50-200 \mathrm{~V}$, with constant $75 \mathrm{~mA} . \mathrm{cm}^{-2}$ of current density for $10 \mathrm{~min}$ of oxidation process at room temperature. The anodised titanium films were characterised using $X$-ray Diffractometer (XRD), field emission scanning electron microscopy (FESEM) and atomic force microscopy (AFM). From this study, it is proven that the strong acid (sulphuric acid) is more effective to be used as electrolyte in order to produce rougher surface (formation of anatase and rutile) compared to weak acid (acetic acid) which able to produce small amount of anatase only.
\end{abstract}

Keywords-Anodic oxidation, titanium, biomaterials, thin film, titania

\section{Introduction}

Titanium has been used widely in various industries including biomedical due to its desirable properties such as excellent mechanical properties, lightweight, high corrosion resistance and biocompatibility [1]. Some application of titanium in biomedical including in orthopedic field which used as artificial hip-joint implant and bone fixation as well in cardiac and cardiovascular where artificial heart valve and stents were made by using titanium [2]. Titanium is a bioinert material; therefore surface modification is needed to change this bioinert to bioactive material in order to enhance the tissue compatibility and mechanically interlocking between implant and bone [3]

The thin oxide layer $(10-15 \mathrm{~nm})$ on the surface of titanium can be formed naturally by exposing Ti to the air [4]. There are many types of surface modification techniques can be applied to titanium to produce bioactive titanium oxide layer (titania or $\mathrm{TiO}_{2}$ ) such as chemical treatment, sol-gel, chemical vapour deposition, thermal spray, ion implantation and deposition, anodic oxidation and many more [5].

Hasan Zuhudi Abdullah

Universiti Tun Hussein Onn Malaysia

Malaysia

Basically, there are three types of polymorphs of titanium; anatase, rutile and brookite [6]. It is proven that anatase and/or rutile crystal structure films showed excellent apatite forming ability and able to produced compact apatite layer covering all surface of titanium after soaking in simulated body fluid (SBF) [7]. The comparison between these three natural polymorphs of titanium oxide; anatase, rutile and brookite, anatase is the most suitable form of photocatalytic activity while brookite normally difficult to obtain during the ceramic processing [8]. Rutile is the stable form of titanium oxide at ambient conditions which possesses unique semiconductor characteristics [9]. The crystalline oxides (anatase and rutile) present several unusual features that become attraction to researcher and industry such as good photocatalytic behavior, superhydrophilicity and biocompatible properties [10].

In order to enhance the interlocking of implant to bone, titanium must possess high crystal structure (anatase and/or rutile), porous and superhydrophilicity surface [11]. Recently, anodic oxidation has proven useful for producing titanium oxide $\left(\mathrm{TiO}_{2}\right)$ coating on titanium substrate and able to enhance the bone conductivity. It works incorporate electrode reactions in combination of electric field metal driven and oxygen ion diffusion to the formation of an oxide film on anode surface. Anodic oxidation technique also allows controlling the formation of oxide layer which is thicker than formed naturally [12]. The anodic oxidation able to increase the thickness of oxide layer which also increase the corrosion resistance of the titanium films. The oxide layer is not only to increase the corrosion resistance (passive oxide layer) of the titanium but also to enhance the conditions of the titanium to be compatible with bone.

Anodisation is a simple techniques that are useful at low temperature for $\mathrm{TiO}_{2}$ production layers on titanium substrates and can be divided into two categories; oxidation at low voltage levels $(<200 \mathrm{~V})$ and high voltage levels (>200V) [13]. Some studies had been done using $\mathrm{H}_{2} \mathrm{SO}_{4}$ as an electrolyte followed by heat treatment and this studied concluded that this process is an effective method to prepare bioactive titanium [14]. After anodic oxidation processes, the surface of the sample was observed to be covered by porous $\mathrm{TiO}_{2}$ (anatase and/or rutile phase). The effect on structures and the properties of the anodic oxides depends on various process parameters. On the other hand, other researchers also compared the crystallinity of $\mathrm{TiO}_{2}$ thick film anodised in $\mathrm{H}_{2} \mathrm{SO}_{4}$. The results showed that phase formation, colour, thicknesses, and microstructures of the films depended strongly on the current density. The anatase phase was observed to form at low current density (5 $\mathrm{mA} / \mathrm{cm}^{2}$ ), and rutile phase was detected at current density more than $60 \mathrm{~mA} / \mathrm{cm}^{2}$ [15]. It is also proven that, by increasing of anodizing time results the higher intensity of corrosion and formed high thickness oxide layer [16].

In the present study, an oxide surface of titanium was modified by anodising the commercially pure titanium (cpTi) in two different electrolytes of acetic and sulphuric acid. The applied voltage was varied to investigate the effect of 
these acids in order to produce bioactive titanium. The oxide surface will be evaluated by using XRD, FESEM and AFM.

\section{Experimental Method}

\section{A. Sample Preparation}

A rectangular samples (with dimensions $25 \mathrm{~mm} \times 10$ $\mathrm{mm}$ and a thickness of $0.05 \mathrm{~mm}$ ) made of a high purity titanium were used as substrates. The surfaces of the samples were polished using 1200 grit $(\sim 1 \mu \mathrm{m})$ silicon carbide (SiC) abrasive paper, followed by cleaning with acetone and distilled water, and drying using compressed air

\section{B. Anodic Oxidation}

The anodic oxidation is done in an electrochemical cell containing $400 \mathrm{ml}$ aqueous solutions of acetic acid $\left(\mathrm{C}_{2} \mathrm{H}_{4} \mathrm{O}_{2}\right.$, AO-A) and sulphuric acid $\left(\mathrm{H}_{2} \mathrm{SO}_{4}, \mathrm{AO}-\mathrm{S}\right)$. The anode and cathode were titanium films and the anodising was done with a programmable power supply (Genesys 600-1.3, Densai-Lambda, Japan). The experimental parameters used are shown in Table I. The anodised titanium was cleaned by dipping in distilled water, followed by drying in still air. Figure 1 shows the schematic apparatus setup of anodic oxidation [17].

TABLE I. PARAMETERS USED FOR ANODIC OXIDATION

\begin{tabular}{||l|c||}
\hline \multicolumn{1}{|c|}{ Parameter } & Value (s) \\
\hline \hline Electrolytes & $\begin{array}{c}\text { Acetic acid }\left(\mathrm{C}_{2} \mathrm{H}_{4} \mathrm{O}_{2}\right), \\
\text { Sulphuric acid }\left(\mathrm{H}_{2} \mathrm{SO}_{4}\right)\end{array}$ \\
\hline Concentration $(\mathrm{M})$ & 0.3 \\
\hline d.c voltage $(\mathrm{V})$ & $50,100,200$ \\
\hline Current density $\left(\mathrm{mA} . \mathrm{cm}^{-2}\right)$ & 75 \\
\hline Duration $(\mathrm{min})$ & 10 \\
\hline
\end{tabular}

\section{Sample Characterisations}

After anodic oxidation, the anodised titanium samples were washed with distilled water, dipping in acetone and

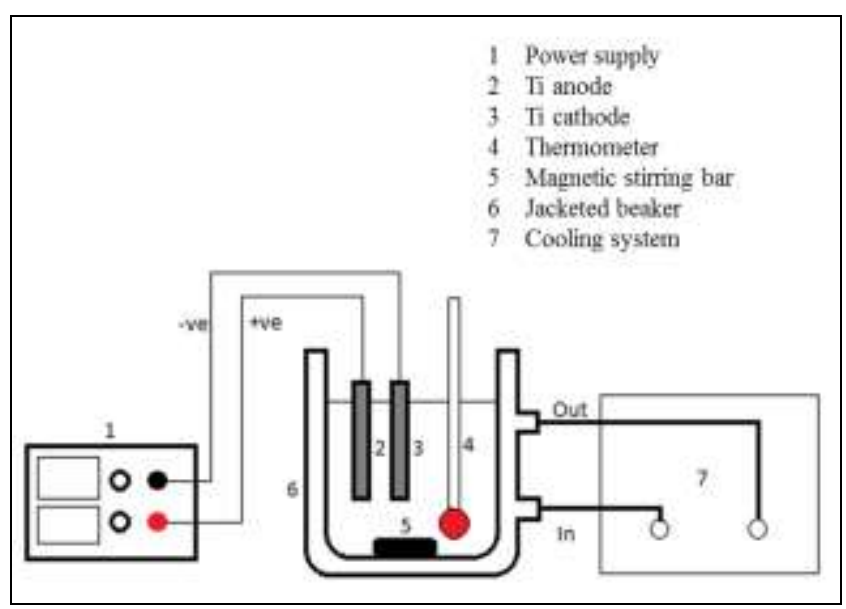

dried in still air before the analysis performs. The mineralogical composition of the films was determined using X-ray diffractometer (XRD; X'Pert ${ }^{3}$ Powder, PANalytical, Netherlands) at $40 \mathrm{kV}$ and $40 \mathrm{~mA}$, angle of incidence of $1^{\circ}$, scanning speed of $0.067 \%$. The microstructures were examined by using field emission scanning electron microscopy (FESEM; JSM-7600F, Joel Ltd., Japan) at an accelerating voltage of $5 \mathrm{kV}$. The surface profile was determined by using atomic force microscopy (AFM; XE-100, Park System, South Korea) with $10 \mu \mathrm{m}$ scanning size, $250-850 \mathrm{~nm}$ wavelength, non-contact measurement mode and $3 \mathrm{~mm}$ distance between cantilever and sample.

\section{Results and Discussion}

\section{A. Mineralogical of Samples}

Figure 2(a) and Figure 2(b) show the XRD patterns of the anodised titanium films under different applied voltage and type of electrolyte at current density of $75 \mathrm{~mA} . \mathrm{cm}^{-2}$. It can be seen from the Figure 2(a) and Figure 2(b) that there were significant effect of applied voltage and type of electrolyte used in formation of anatase and/or rutile phase on the titanium film surface. Anatase was detected when the applied voltage of oxidation process more than $200 \mathrm{~V}$ and $100 \mathrm{~V}$ for AO-A and AO-S respectively

During the anodic oxidation, micro-arc sparkling occurred on $200 \mathrm{~V}$ of AO-S sample. This leads to formation of mixture anatase and rutile on titanium film surface. It is also observed that the crystalline structure of anatase phase are higher for AO-S compared to samples AO-A at $100 \mathrm{~V}$. From Figure 2(b), mixture of anatase and rutile was observed on the sample formed in $\mathrm{H}_{2} \mathrm{SO}_{4}$ electrolyte solution at $200 \mathrm{~V}$. This happened due to localised heating occurred which leads to micro-arc sparkling resulted rutile phase becomes more stable than anatase. A weak acid (acetic acid) is able to form a thin anatase structure under low voltage $(<200 \mathrm{~V})$. Meanwhile, a high voltage $(\geq 200 \mathrm{~V})$ was used to formed high crystalline structure of anatase on titanium film surface. Furthermore, different type of electrolyte being used for anodic oxidation process with same applied voltage and current density produced different crystalline structure on the samples. The results as shown in Figure 2(a) and Figure 2(b) indicated that the amount of anatase and rutile increased with increment of applied voltage for both electrolytes.

In anodic oxidation, oxygen from the acidic electrolyte is produced at the anode and this can react with the metal to thicken the metal oxide layer ( $\mathrm{Ti}^{4+}$ ions). The result indicated that the higher the voltage, the thicker (more porous) the oxide layer and amount of anatase produced. Sulphuric acid (fully ionise) also have better corrosiveness when used as electrolyte compared to acetic acid (not fully ionise) due to its proton (hydrogen ion) capabilities to be transferred to a water molecule to produce hydroxonium ion. The summary of XRD analysis was tabulated in Table II.

Figure 1. Schematic apparatus setup of anodic oxidation [17]. 
Proc. of the Third Intl. Conf. Advances in Civil, Structural and Mechanical Engineering- CSM 2015

Copyright (C) Institute of Research Engineers and Doctors, USA .All rights reserved.

ISBN: 978-1-63248-062-0 doi: 10.15224/ 978-1-63248-062-0-33

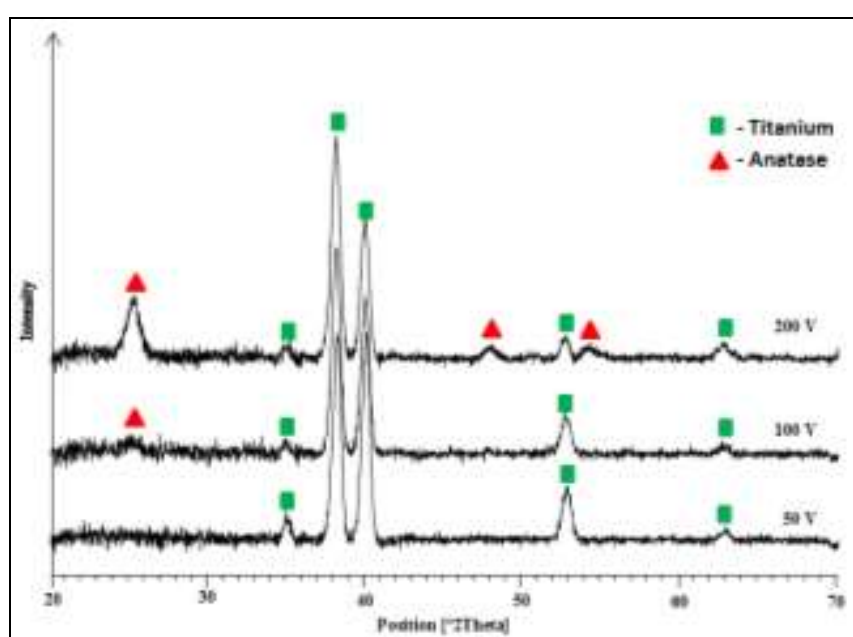

(a)

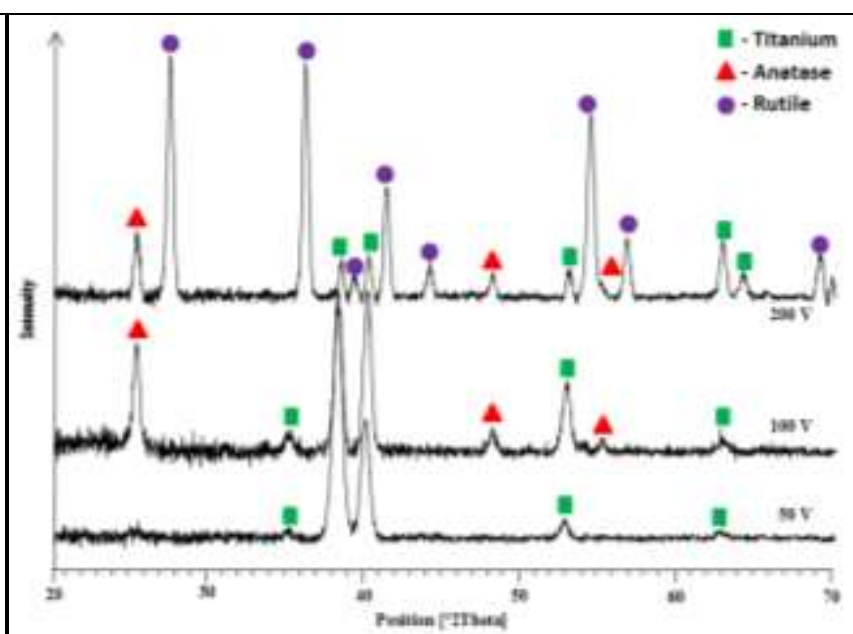

(b)

Figure 2. XRD analysis of anodised samples at $75 \mathrm{~mA} \cdot \mathrm{cm}^{-2}$ in; (a) $\mathrm{C}_{2} \mathrm{H}_{4} \mathrm{O}_{2}$ and (b) $\mathrm{H}_{2} \mathrm{SO}_{4}$.

TABLE II. SUMMARY OF XRD ANALYSIS

\begin{tabular}{||c|c|c||}
\hline $\begin{array}{c}\text { Voltage } \\
\text { (V) }\end{array}$ & AO-A & AO-S \\
\hline \hline $\mathbf{5 0}$ & \multicolumn{2}{|c|}{ No anatase and rutile form } \\
\hline $\mathbf{1 0 0}$ & $\begin{array}{c}\text { Very low of anatase } \\
\text { formed }\end{array}$ & $\begin{array}{c}\text { High crystalline of anatase } \\
\text { observed }\end{array}$ \\
\hline $\mathbf{2 0 0}$ & $\begin{array}{c}\text { Better anatase was } \\
\text { detected than 100 V }\end{array}$ & $\begin{array}{c}\text { Mixture of anatase and } \\
\text { rutile were identified }\end{array}$ \\
\hline
\end{tabular}

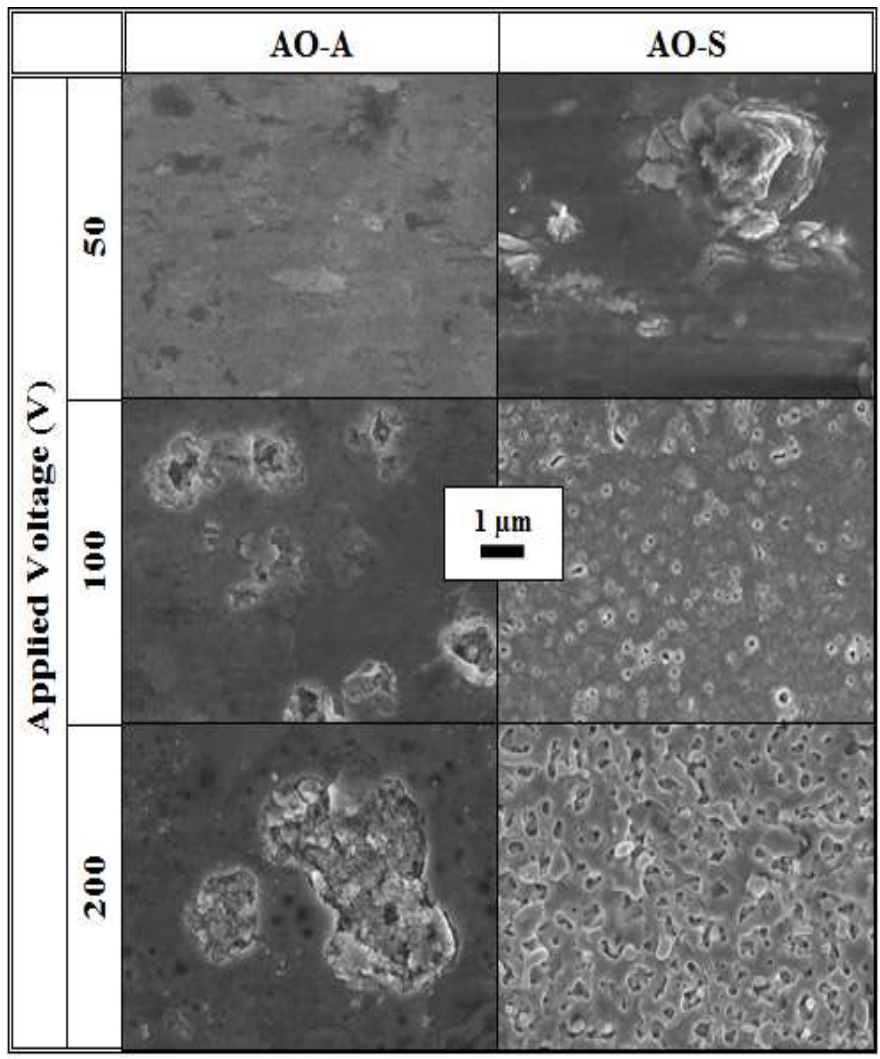

Figure 3. FESEM micrographs of anodised titanium in $\mathrm{C}_{2} \mathrm{H}_{4} \mathrm{O}_{2}$ (AO-A) and $\mathrm{H}_{2} \mathrm{SO}_{4}\left(\mathrm{AO}-\mathrm{S}\right.$ ) at $75 \mathrm{~mA} . \mathrm{cm}^{-2}$.

\section{B. Surface Morphological of Samples}

Figure 3 shows the surface morphologies of the anodic films obtained from oxidation process in different electrolyte and applied voltage observed by FESEM. For sample prepared using AO-A, a smooth and clear polishing effect can be seen at $50 \mathrm{~V}$. Applied voltage of $100 \mathrm{~V}$ is the onset of anodising effect where some craters are formed on certain area of titanium surface. The anodising effect (crater) becomes bigger and there are many pores observed on the sample surface with increment of applied voltage up to 200 V.

After anodic oxidation in $\mathrm{H}_{2} \mathrm{SO}_{4}$, the anodising effect is seen on titanium surface at $50 \mathrm{~V}$. There are many pores observed on the titanium films at $100 \mathrm{~V}$, where mixture of small open and close pores were formed covering the surface of the specimen. At $200 \mathrm{~V}$, an oxide layer with three-dimensional oxide structure consisting of numerous open pores formed on the surface of titanium sample. During this process, gas evaluation and spark discharged occurred. It is increased the size and number of pores formed on the sample, which increased the surface roughness of the specimen.

The oxide layer became thicker after the oxidation reaction increasing due to the oxygen ion diffusion $\left(\mathrm{O}_{2}\right.$ ions $)$ transferred into the titanium interface and migration of $\mathrm{Ti}^{4+}$ ions from the titanium substrate to the film/electrolyte interface at the anode. From the Figure 3, it shows that the anodic oxidation able to change smooth surface of titanium to rough surface by increasing the applied voltage of the system. Apart from that, strong acid (sulphuric acid) is more efficient to produce rougher surface compared to weak acid (acetic acid). The three-dimensional oxide structure at $200 \mathrm{~V}$ of AO-S provided better nucleation site for apatite formation when soak in simulated body fluid [17]. This will enhance the interlocking of implant to bone when implanted inside human body as artificial implant. From these results, it shows that AO-A need higher potential energy to breakdown the dielectric layer to produce more porous surface for high crystalline of anatase and/rutile to be formed on titanium surface and vice versa for AO-S. 
Proc. of the Third Intl. Conf. Advances in Civil, Structural and Mechanical Engineering- CSM 2015 Copyright (C) Institute of Research Engineers and Doctors, USA .All rights reserved.

ISBN: 978-1-63248-062-0 doi: 10.15224/ 978-1-63248-062-0-33

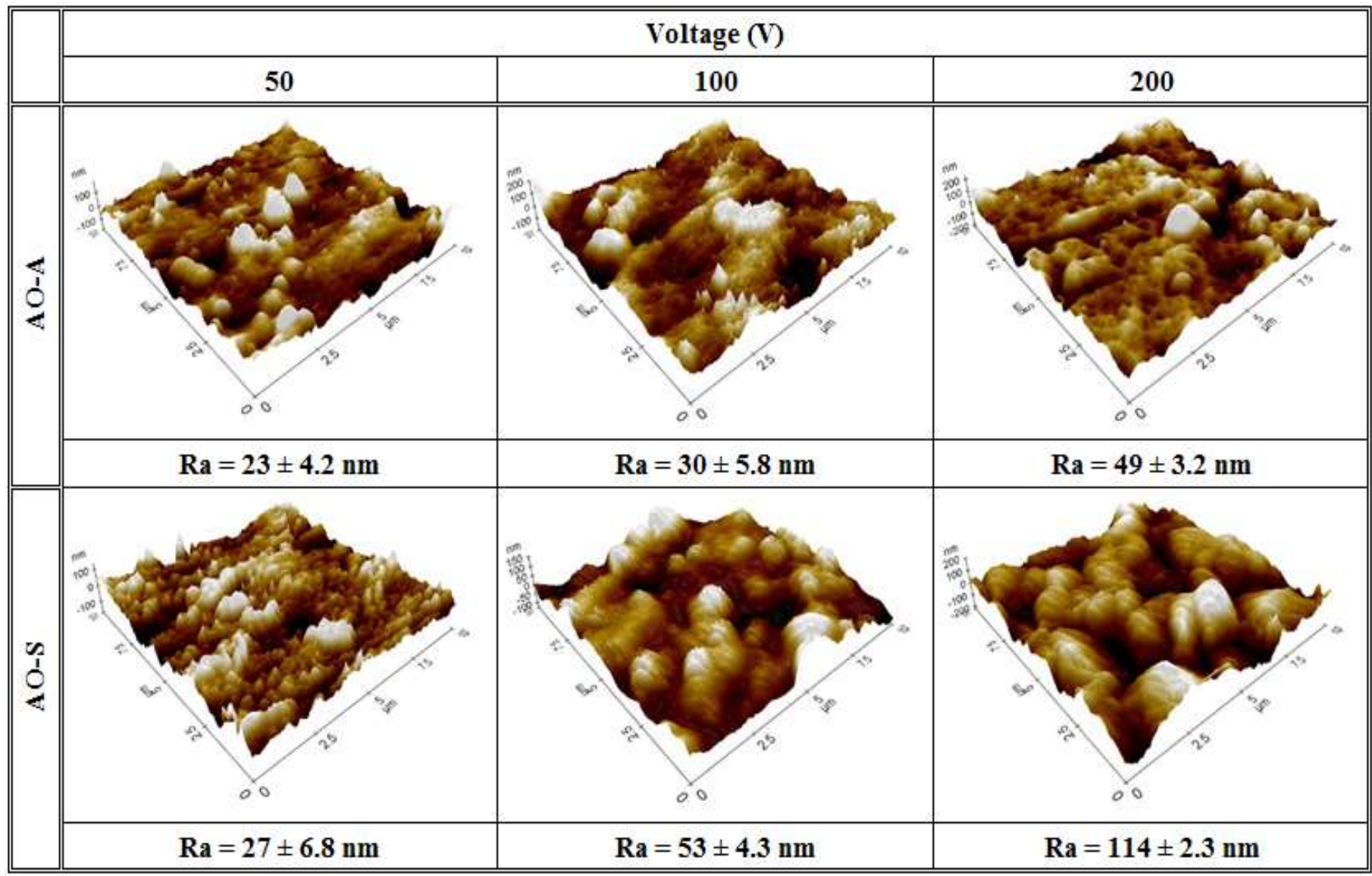

Figure 4. AFM images of anodised titanium in $\mathrm{C}_{2} \mathrm{H}_{4} \mathrm{O}_{2}$ (AO-A) and $\mathrm{H}_{2} \mathrm{SO}_{4}$ (AO-S) at $75 \mathrm{~mA} \cdot \mathrm{cm}^{-2}$.

\section{Surface Profile of Samples}

Numerous open pores formed on the surface of titanium under certain conditions and increment of pore size also the existence of white subsurface leads increment of surface roughness (Ra). From Figure 4, At $50 \mathrm{~V}$ of AO-A, there are some scratches valley (effect from polishing) still visible on three-dimensional AFM images. The amount of oxide formed on the titanium surface for AO-A was increased with increment of applied voltage and makes the polishing effect unseen. The shape of oxide also changed from small and shard oxide at $50 \mathrm{~V}$ to dented (volcano shaped), uneven and big oxide at $200 \mathrm{~V}$ which covered all surface of the titanium. The surface roughness of the specimen also increased when the applied voltage was increased. This result supported by the XRD and FESEM results.

For AO-S, at $50 \mathrm{~V}$ there are numerous small and sharp oxides formed on the titanium surface and the polishing effect is unseen on this sample. This oxide change to big and scatter oxide when the applied voltage increased to $100 \mathrm{~V}$. There are some black spots on the sample surface due to open pores as shown in Figure 2 of FESEM result. At 200 $\mathrm{V}$, the big oxides merge to formed network of oxide and black spots became more seen compared to $100 \mathrm{~V}$ due to overlap oxides, number of open pores increased and covered almost all area of the titanium surface.

Figure 4 indicated that the surface roughness $(\mathrm{Ra})$ of AO-A slightly increased when the applied voltage increased from $23 \pm 4.2 \mathrm{~nm}(50 \mathrm{~V})$ to $49 \pm 3.2 \mathrm{~nm}(200 \mathrm{~V})$. While for $\mathrm{AO}-\mathrm{S}$, the Ra increased drastically from $27 \pm 6.8 \mathrm{~nm}$ at $50 \mathrm{~V}$ to $114 \pm 2.3 \mathrm{~nm}(200 \mathrm{~V})$. There is a huge different of $\mathrm{Ra}$ value for AO-A and AO-S at voltage $100 \mathrm{~V}$ and $200 \mathrm{~V}$. This happened due to type of electrolyte been used. The electrolyte itself had different oxygen ion diffusion potential, where AO-S have better ionise than AO-A as mentioned in previous analysis.

\section{Conclusions}

In conclusion, this paper presented works on preparing bioactive titanium from bioinert by performed surface modification via simple anodic oxidation process, which able to convert the amorphous oxide of titanium into an anatase or mixture with rutile. From this study, it shows that the sulphuric acid is and optimal electrolyte when the aim of the study is to obtain anatase crystalline on the titanium film compared to acetic acid. This electrolyte able to formed porous surface with anatase even at some cases up to mixture with rutile crystalline without preforming and additional treatment (heat or alkaline treatment) or technique for conversion of an amorphous oxide.

From the study, both AO-A and AO-S sample are greatly affected by high potential of anodising (applied voltage). Different types of electrolyte also lead to differed result even the other parameters are same. The applied voltage and type of electrolyte of anodic oxidation affects the surface morphology and crystallinity of the titanium. Porous surface and anatase and/or rutile was formed on the titanium surface when the applied voltage $\geq 100 \mathrm{~V}$ for AO-S. While for AO$\mathrm{S}$, this electrolyte only able to produce small amount of anatase even the applied voltage is $200 \mathrm{~V}$, which needs other treatment to enhance the surface properties of the titanium. 
Finally, the applied voltage and type of electrolyte of anodic oxidation plays an important role in the formation of anatase of $\mathrm{Ti}$ specimen. The surface roughness of the $\mathrm{Ti}$ specimens was increased with increment of applied voltage. More porous surfaces of Ti will lead more sites for apatite formation. It can be conclude that, the surface morphology and profile of Ti films were strongly affected by the applied voltage and type of electrolyte to meet clinical need by changing the smooth surface of $\mathrm{Ti}$ to rough/porous, where this kind of surface able to provide more site for apatite formation when implanted inside human body as biomaterial.

\section{Acknowledgment}

The author would like to acknowledge the support of Ministry of Higher Education of Malaysia (MOHE) for funding the current research grant, FRGS Vot 1419 and FRGS Vot 1212 for performing this work. All those who contributed directly or indirectly are thanked.

\section{References}

[1] E. Santos, N.K. Kuromoto, and G.A. Soares, "Mechanical properties of titania films used as biomaterials", Materials, Chemical \& Physicals, vol. 102, pp. 92-97, 2007

[2] T. Kizuki, H. Takadama, T. Matsushita, T. Nakamura, and T. Kokubo, "Preparation of bioactive $\mathrm{Ti}$ metal surface enriched with calcium ions by chemical treatment", Acta Biomaterialia, vol. 6, pp. 2836-2842, 2010.

[3] K.J. Tan, H.Z. Abdullah, M.I. Idris, and C.C. Sorrell, "Gel oxidation of titanium at low concentration of sodium hydroxide $(\mathrm{NaOH})$ ", Advanced Materials Research, vol. 1087, pp. 340-344, 2015.

[4] M. Keshmiri and T. Troczynski, "Apatite formation on $\mathrm{TiO}_{2}$ anatase microspheres", Non-Crystalline Solids, vol. 324, pp. 289-294, 2003.

[5] X. Liu, P.K. Chu, and C. Ding, "Surface modification of titanium, titanium alloys, and related materials for biomedical applications", Materials Science \& Engineering R., vol 47, pp. 49-121, 2004.

[6] W. Payakgul, O. Mekasuwandumrong, V. Pavarajarna, and P. Praserthdama, "Effect of reaction medium on the synthesis of $\mathrm{TiO}_{2}$ nanocrystals by thermal decomposition of titanium (IV) n-butoxide:", Ceramics International, vol. 31, pp. 391-397, 2005.

[7] H.J. Song, S.H. Park, S.H. Jeong, and Y.J. Park, "Surface characteristics and bioactivity of oxide films formed by anodic spark oxidation on titanium in different electrolytes", Materials Processing Technology, vol. 209, pp. 864-870, 2009.

[8] A. Ravaglioli and A. Krajewski, "Bioceramics: Materials, Properties, Application”, Chapman \& Hall, London, 1992.

[9] H. Wu, X. Lu, B. Long, X. Wang, J. Wang, and Z. Jin, "The effect of cathodic and anodic voltages on the characteristics of porous nanocrystalline titania coatings fabricated by micro arc oxidation:", Materials Letters,vol. 59, pp. 370-375, 2005.

[10] Y. Mizukoshi, and N. Masahashi, "Fabrication of a $\mathrm{TiO}_{2}$ photocatalys by anodic oxidation of $\mathrm{Ti}$ in an acetic acid electrolyte", Surface \& Coatings Technology, vol. 240, pp. 226-232, 2014.

[11] T.C. Lee, M.I. Idris, H.Z. Abdullah, and C.C. Sorrell, "Effect of electrolyte concentration on anodised titanium in mixture $\beta$ Glycerophosphate ( $\beta$-GP) and Calcium Acetate (CA)", Advanced Materials Research, vol. 1087, pp. 116-120, 2015.

[12] M.A. Selimin, N.H.M. Idrus, and H.Z. Abdullah, "Anodic oxidation of titanium for biomedical application", Advanced Materials Research, vol. 1087, pp. 81-85, 2015.

[13] I.S. Park, T.G. Woo, M.H. Lee, S.G. Ahn, M.S. Park, T.S Bae, and K.W. Seol, "Effects of anodizing voltage on the anodized and hydrothermally treated titanium surface", Metals and Materials International, vol. 12, pp. 505-511, 2006.

[14] B. Yang, M. Uchida, H.M. Kim, X. Zhang, and T. Kokubo, "Preparation of bioactive titanium metal via anodic oxidation treatment", Biomaterials, vol. 25, pp. 1003-1010, 2004.
[15] I.S. Park, M.H. Lee. T.S. Bae, and K.W. Seol, "Effects of anodic oxidation parameters on a modified titanium surface", Journal of Biomedical Research Part B: Applied Biomaterials,vol. 84, pp. 422428, 2008.

[16] H.Z. Abdullah, and C.C. Sorrell, "Preparation and characterisation of tio2 thick films fabricated by anodic oxidation," Material Science Forum, vol. 561, pp. 2159-2162, 2007.

[17] H.Z. Abdullah, P. Koshy, and C.C. Sorrell, "Anodic oxidation of titanium in mixture of $\beta$-glycerophosphate $(\beta-\mathrm{GP})$ and calcium acetate (CA)", Key Engineering Materials, vol 275, pp. 594-595, 2014.

[18] X. Cui, H.M. Kim, M. Kawashita, L. Wang, T. Xiong, T. Kokubo, and T. Nakamura, "Preparation of bioactive titanium films on titanium metal via anodic oxidation", Dental Materials, vol. 25, pp. 80-86, 2009. 